\title{
Glucocorticoid Receptor-Mediated Suppression of Activator Protein-1 Activation and Matrix Metalloproteinase Expression after Spinal Cord Injury
}

\author{
Jan Xu, ${ }^{1}$ Gyeong-Moon Kim, ${ }^{1}$ S. Hinan Ahmed, ${ }^{1}$ Jinming Xu, ${ }^{1}$ Ping Yan, ${ }^{2}$ Xiao Ming Xu, ${ }^{2}$ and Chung Y. Hsu ${ }^{1}$ \\ ${ }^{1}$ Department of Neurology and Center for the Study of Nervous System Injury, Washington University School of Medicine, \\ St. Louis, Missouri 63110, and 2Department of Anatomy and Neurobiology, Saint Louis University School of Medicine, St. \\ Louis, Missouri 63104
}

\begin{abstract}
Post-traumatic inflammatory reaction may contribute to progressive tissue damage after spinal cord injury (SCl). Two key transcription factors, nuclear factor $\kappa \mathrm{B}(\mathrm{NF}-\kappa \mathrm{B})$ and activator protein-1 (AP-1), are activated in inflammation. An increase in $\mathrm{NF}-\kappa \mathrm{B}$ binding activity has been shown in the injured spinal cord. We report activation of AP-1 after SCl. Electrophoretic mobility shift assay showed that AP-1 binding activity increased after $\mathrm{SCl}$, starting at $1 \mathrm{hr}$, peaking at $8 \mathrm{hr}$, and declining to basal levels by $7 \mathrm{~d}$. Methylprednisolone (MP) is the only therapeutic agent approved by the Food and Drug Administration for treating patients with acute traumatic $\mathrm{SCl}$. MP reduced posttraumatic AP-1 activation. RU486, a glucocorticoid receptor (GR) antagonist, reversed MP inhibition of AP-1 activation. Immunostaining showed an increase in the expression of the Fos-B and C-Jun components of AP-1 in the injured cord. A $c$-fos antisense oligodeoxynucleotide (ODN) inhibited AP-1, but
\end{abstract}

not NF- $\kappa \mathrm{B}$, activation after $\mathrm{SCl}$. AP-1 and $\mathrm{NF}-\kappa \mathrm{B}$ can transactivate genes encoding matrix metalloproteinase-1 (MMP-1) and MMP-9. Western blotting and immunostaining show increased expression of MMP-1 and MMP-9 in the injured cord. MP inhibited MMP-1 and MMP-9 expression after SCl. RU486 reversed this MP effect. The $c$-fos antisense ODN, however, failed to suppress MMP-1 or MMP-9 expression. These findings demonstrate that MP may suppress post-traumatic inflammatory reaction by inhibiting both the AP-1 and NF- $\kappa$ B transcription cascades via a GR mechanism. Expression of inflammatory genes such as MMP-1 and MMP-9 that are transactivated jointly by AP- 1 and NF- $\kappa$ B may not be suppressed by inhibiting only AP-1 activity.

Key words: inflammation; methylprednisolone; NF-кB; protease; RU486; transcription factor
Methylprednisolone (MP), a synthetic glucocorticoid (GC), is the only therapeutic agent approved by the Food and Drug Administration (FDA) for the treatment of acute traumatic spinal cord injury (SCI) in humans (Bracken, 1990). However, the effect of MP in SCI is modest (Nesathurai, 1998), and its mechanism of action remains to be fully delineated. GCs including MP are anti-inflammatory agents with a wide range of useful clinical applications (Barnes, 1998). A post-traumatic inflammatory reaction has been extensively documented in animal SCI models (Balentine, 1978a,b; Means and Anderson, 1983; Xu et al., 1990; Blight, 1992; Dusart and Schwab, 1994; Bartholdi and Schwab, 1995; Hamada et al., 1996; Popovich et al., 1996, 1997; Zhang et al., 1997). Inhibition of lipid peroxidation (Hall and Braughler, 1981) and inflammatory reaction (Hsu and Dimitrijevic, 1990; Bartholdi and Schwab, 1995) are thought to contribute to the therapeutic effects of MP in SCI. GC suppression of inflammation is mediated by a glucocorticoid receptor (GR) mechanism. GCs, functioning as ligands, bind to the cytosolic GR to form activated GR (aGR) (Barnes, 1998). aGR is an anti-inflammatory transcription factor that inhibits the activation of two major proinflammatory transcription factors, nuclear factor $\kappa \mathrm{B}(\mathrm{NF}-\kappa \mathrm{B})$ and

Received May 9, 2000; revised Oct. 4, 2000; accepted Oct. 11, 2000.

This study was supported in part by National Institutes of Health Grants NS37230 and NS36350 and also by the International Spinal Research Trust.

Correspondence should be addressed to Dr. Chung Y. Hsu, Department of Neurology, Washington University, School of Medicine, Box 8111, 660 South Euclid Avenue, St. Louis, MO 63110. E-mail: hsuc@neuro.wustl.edu.

Copyright (C) 2001 Society for Neuroscience $0270-6474 / 01 / 210092-06 \$ 15.00 / 0$ activator protein-1 (AP-1) (Jonat et al., 1990; Schule et al., 1990; Yang-Yen et al., 1990; Ray and Prefontaine, 1994; Caldenhoven et al., 1995; Scheinman et al., 1995).

$\mathrm{NF}-\kappa \mathrm{B}$ activation, known to transactivate proinflammatory genes, including those encoding cytokines, adhesion molecules, inducible nitric oxide synthase, and others in immune and inflammatory processes, has been demonstrated in the injured cord (Bethea et al., 1998; Xu et al., 1998). NF- $\kappa$ B activation after SCI was suppressed by MP (Xu et al., 1998). AP-1 activation after SCI, however, has not been studied previously. AP-1 is a dimer composed of various Fos and Jun family proteins (Chiu et al., 1988; Halazonetis et al., 1988). Immediate early genes of the fos and jun families are upregulated after ischemic and traumatic CNS injury (An et al., 1993; Yang et al., 1994). AP-1, functioning as a proinflammatory transcription factor, transactivates a number of genes that are expressed in inflammation (Karin et al., 1997; Wisdom, 1999). Among these are genes encoding matrix metalloproteinases (MMPs) (Jonat et al., 1990; Schule et al., 1990; Yang-Yen et al., 1990; Sato et al., 1993; Yokoo and Kitamura, 1996). Excessive MMP expression leads to increased capillary permeability in numerous neurological disorders such as multiple sclerosis, infection, and ischemia (Yong et al., 1998). Alteration of vascular permeability, a key feature of inflammation, has been noted after SCI (Hsu et al., 1985).

In this study we examined the impact of SCI on AP-1 transactivation of downstream genes MMP-1 and MMP-9, as gauged by MMP-1 and MMP-9 protein expression. Because GR activation mediates the inhibition of NF- $\kappa$ B and AP-1 (Barnes, 1998), and 
GR expression is increased after SCI (Yan et al., 1999), we also explored whether the activation of the AP-1 cascade after SCI could be modulated by a GR mechanism.

\section{MATERIALS AND METHODS}

Spinal cord injury model. A total of 91 female Long-Evans rats $(240 \pm 40$ gm; Simonsen Laboratories, Gilroy, CA) were used for the present study. All surgical procedures and animal experimentation protocols followed the Laboratory Animal Welfare Act, the Guide for the Care and Use of Laboratory Animals (National Research Council, 1996), and the Guidelines and Policies for Rodent Survival Surgery provided by the Animal Studies Committee of Washington University School of Medicine. The method for inducing SCI followed the Multicenter Animal Spinal Cord Injury Study (MASCIS) protocol (Basso et al., 1996) as reported previously (Liu et al., 1997). Briefly, rats were anesthetized with pentobarbital $(35-45 \mathrm{mg} / \mathrm{kg}$ ), and a laminectomy was made at the T-10 segment. Using a New York University Impactor, SCI was induced by dropping a $10 \mathrm{gm}$ weight at a height of $12.5 \mathrm{~mm}$ (Gruner, 1992). Animals subjected to identical surgical procedures without injury served as sham-operated controls. In addition, animals that received no surgery were also included as normal controls. Postoperative care, including bladder management, was detailed previously (Liu et al., 1997; Yan et al., 1999).

Treatment protocols. Animals were treated with MP intravenously at a dose of $30 \mathrm{mg} / \mathrm{kg}, 15 \mathrm{~min}$ after injury. Rats given the vehicle only served as controls. In selected group of MP-treated rats, RU486 $(15 \mathrm{mg} / \mathrm{kg}$; Sigma, St. Louis, MO) was administered via an intraperitoneal route 30 min before injury. A separate group of animals were treated with an antisense or sense phosphorothioated oligodeoxynucleotide (ODN) to $c$-fos. The ODNs were custom-made by Life Technologies (Gaithersburg, MD): sense orientation (sense-rncfosr115) 5' ggtttgcccaaaccacgaccatgatg- $3^{\prime}-\mathrm{OH}$ and antisense orientation (antisenserncfosr115) 5'-catcatggtcgtggtttgggcaaacc-3'-OH (Liu et al., 1994; Cui et al., 1999). The antisense or sense ODN in a volume of $2.5 \mu \mathrm{l}(2 \mu \mathrm{l}$ of 1 $\mu \mathrm{M}$ ODN in PBS, pH 7.4, mixed with $0.5 \mu \mathrm{l}$ of $1 \mathrm{mg} / \mathrm{ml}$ lipofectin) was infused into the rat spinal cord directly with the needle tip at the depth of $1.5 \mathrm{~mm}$ from the dorsal midline surface under the guidance of a stereotaxic device $16 \mathrm{hr}$ before injury. The infusion rate was $1 \mu \mathrm{l} / \mathrm{min}$, and the needle was withdrawn 5 min after completion of ODN delivery. An identical volume of the vehicle $(2 \mu \mathrm{l}$ PBS mixed with $0.5 \mu \mathrm{l}$ of $1 \mathrm{mg} / \mathrm{ml}$ lipofectin) was infused in another set of control animals.

Isolation of nuclear proteins. An $8 \mathrm{~mm}$ cord segment $(4 \mathrm{~mm}$ rostral and 4 $\mathrm{mm}$ caudal from the epicenter) was dissected and immediately frozen after the animal was killed under anesthesia at various time points ranging from $1 \mathrm{hr}$ to $7 \mathrm{~d}$ after SCI. Nuclear protein extraction followed the high-salt method described previously (Dignam et al., 1983) with modifications (An et al., 1993; Yan et al., 1999). Homogenization and extraction conditions have been established and detailed elsewhere (An et al., 1993).

Electrophoretic mobility shift assay. AP-1 binding activity was assessed by electrophoretic mobility shift assay (EMSA) as reported previously (An et al., 1993; Yan et al., 1999). The following AP-1 consensus oligonucleotide was used: 5'-CGCTTGATGAGTCAGCCGGAA-3' (Promega, Madison, WI). The AP-1 oligonucleotide was labeled with $\gamma-{ }^{32} \mathrm{P}[\mathrm{ATP}]$ according to Promega technical bulletin number 106 . The binding reaction was performed in $20 \mu \mathrm{l}$ of binding buffer (in mM: 10 Tris- $\mathrm{HCl}, 20$ $\mathrm{NaCl}, 1$ DTT, and 1 EDTA, with 5\% glycerol, $\mathrm{pH}$ 7.6) containing 0.0175 pmol of the labeled probe $(>10,000 \mathrm{cpm}), 20 \mu \mathrm{g}$ of nuclear protein and $1 \mu \mathrm{g}$ of poly dIdC. After incubation for $20 \mathrm{~min}$ at room temperature, the reaction mixture was subjected to electrophoresis on a nondenaturing $6 \%$ polyacrylamide gel at $180 \mathrm{~V}$ for $2 \mathrm{hr}$ under low ionic strength conditions. The gel was dried and subjected to autoradiography as described previously (An et al., 1993; Yan et al., 1999). EMSA for NF- $\kappa$ B followed the same procedure with the exception that a different oligonucleotide was used: 5'-AGTTGAGGGGACTTTCCCAGGC-3' (Xu et al., 1998). A total of 51 rats were used in this study.

Western blotting. An $8 \mathrm{~mm}$ spinal cord segment $(4 \mathrm{~mm}$ rostral and $4 \mathrm{~mm}$ caudal from the epicenter) was dissected after intracardial perfusion with $200 \mathrm{ml}$ of saline under anesthesia. Western blotting followed the previously described procedures (Xu et al., 1998; Yan et al., 1999). Briefly, the cord segment was homogenized in $0.1 \mathrm{ml}$ of Western blotting buffer (in mM: $10 \mathrm{HEPES}, 1.5 \mathrm{MgCl}_{2}, 10 \mathrm{KCl}$, and $0.5 \mathrm{DTT}$, with $1 \mu \mathrm{g} / \mathrm{ml}$ leupeptin and $1 \mu \mathrm{g} / \mathrm{ml}$ aprotinin, $\mathrm{pH}$ 7.9) and centrifuged at 14,000 $\times \mathrm{g}$. Twenty micrograms of protein from the supernatant of each sample was loaded onto $8 \%$ polyacrylamide gel, separated by SDS-PAGE, and trans- ferred to a polyvinylidene difluoride membrane by electrophoresis. The membrane was blocked in TBST buffer $(20 \mathrm{~mm}$ Tris-HCl, $5 \%$ nonfat milk, $150 \mathrm{~mm} \mathrm{NaCl}$, and $0.05 \%$ Tween $20, \mathrm{pH} \mathrm{7.5)}$ for $1 \mathrm{hr}$ at room temperature. The primary monoclonal anti-MMP-1 antibody (1:1000; Oncogene, Cambridge, MA) or monoclonal anti-MMP-9 antibody (1: 300; Oncogene) was added to the membrane and incubated for $2 \mathrm{hr}$ at room temperature. The membrane was washed with TBST three times at 10 min intervals, incubated with a secondary alkaline phosphataseconjugated goat anti-mouse IgG antibody (1:5000; Promega) for $1 \mathrm{hr}$, then washed three times each at 10 min intervals with TBST and two times each for 2 min with TBS (TBST without Tween 20). The blot was visualized using the Blot AP System color reaction as described in the technical manual provided by Promega. A total of 24 rats were used in this study.

Immunohistochemical staining. The rats were overdosed with an intraperitoneal injection of pentobarbital sodium $(100 \mathrm{mg} / \mathrm{kg})$. Intracardial perfusion fixation was performed first with $150 \mathrm{ml}$ of physiological saline followed by $400 \mathrm{ml}$ of $4 \%$ paraformaldehyde. The spinal cord was carefully dissected, and an $3 \mathrm{~cm}$ segment containing the injured epicenter was blocked, post-fixed for $2 \mathrm{hr}$ in the same fixatives, and transferred to a solution containing $30 \%$ sucrose in $0.01 \mathrm{M}$ PBS for immunostaining. The cord segment 5-7 mm rostral to lesion epicenter was then embedded in tissue freezing medium (Sakura Finetek, Torrance, CA), cut horizontally at a $10 \mu \mathrm{m}$ interval on a cryostat, and mounted on Superfrost/plus slides (Fisher Scientific, Pittsburgh, PA). Before incubation with primary antibodies, the sections were permeabilized with $0.3 \%$ Triton $\mathrm{X}-100 / 10 \%$ normal horse serum in $0.01 \mathrm{M}$ PBS for $20 \mathrm{~min}$. A goat polyclonal Fos-B antibody (1:200; Santa Cruz Biotechnology, Santa Cruz, CA), rabbit polyclonal c-Jun antibody (1:200; Santa Cruz Biotechnology), mouse monoclonal anti-MMP-1 antibody (1:500; Oncogene), or mouse monoclonal anti-MMP-9 antibody (1:100; Oncogene) was then applied to the sections overnight at $4^{\circ} \mathrm{C}$. The next day, sections were incubated with a secondary biotinylated antibody (Vector Laboratories, Burlingame, CA) for $1 \mathrm{hr}$. After washing, sections were incubated with ABC Elite complex (Vector Laboratories) for $1 \mathrm{hr}$. The staining was visualized with DAB (Sigma). Slides were washed, dehydrated, cleared in xylene, mounted, and examined under an Olympus (Tokyo, Japan) BX60 light microscope. In negative control sections, the primary antibodies were substituted by normal serum in $0.01 \mathrm{M}$ PBS, and, when applicable, they were preabsorbed with the antigen (Fos-B). A total of 16 rats were used in this study.

\section{RESULTS}

\section{AP-1 activation after spinal cord injury}

A low basal level of AP-1 binding activity could be detected in the normal control and sham-operated cords. SCI resulted in a substantial increase in AP-1 activity in a time-dependent manner starting at $1 \mathrm{hr}$ and peaking at $8 \mathrm{hr}$ after SCI. Increase in AP-1 activity was still evident up to $3 \mathrm{~d}$ after SCI but returned to the basal level by $7 \mathrm{~d}$ (Fig. 1A). The criteria for establishing the validity of AP-1 binding activity has been detailed elsewhere (An et al., 1993; Liu et al., 1994). The specificity of AP-1 binding activity is demonstrated by complete abolishment of the AP-1 band in the presence of 200-fold excess of cold AP-1 oligonucleotide (data not shown) (An et al., 1993) or by a c-fos antisense strategy (see below).

\section{Effect of MP and RU486 on AP-1 activation after SCI}

GC suppression of inflammation is mediated by a GR mechanism acting mainly through transrepression of proinflammatory genes driven by two key transcription factors, NF- $\kappa$ B and AP-1 (Jonat et al., 1990; Schule et al., 1990; Yang-Yen et al., 1990; Ray and Prefontaine, 1994; Caldenhoven et al., 1995; Scheinman et al., 1995; Barnes, 1998). NF- $\kappa \mathrm{B}$ activation has been shown in SCI (Bethea et al., 1998; Xu et al., 1998) and could be inhibited by MP treatment (Xu et al., 1998). In the present study, MP (30 mg/ kg) also inhibited AP-1 activation after SCI (Fig. 1B). RU486, a potent GR antagonist, reversed anti-inflammatory effects of GCs by blocking aGR-mediated actions (Laue et al., 1988; Jewell et al., 
$\mathbf{A}$
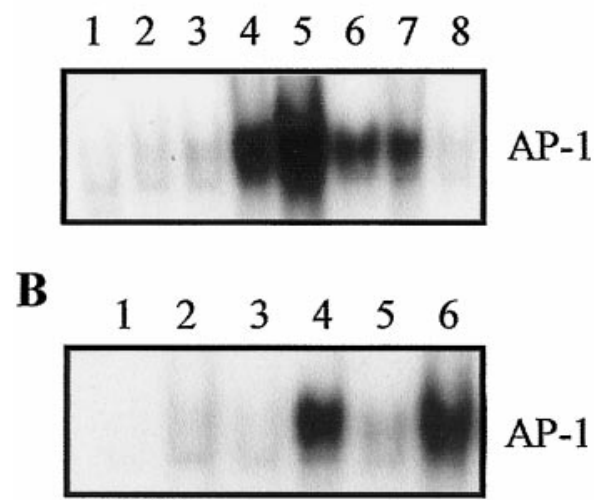

Figure 1. A, Time-dependent changes in AP-1 binding activity after SCI based on EMSA. Lanes 1, Normal control; 2, sham-operated control; 3, 1 hr; 4, $4 \mathrm{hr} ; 5,8 \mathrm{hr} ; 6,1 \mathrm{~d} ; 7,3 \mathrm{~d}$; and 8, $7 \mathrm{~d}$ after SCI. Note progressive increase in AP-1 binding activity starting at $1 \mathrm{hr}$ and peaking at $8 \mathrm{hr}$. AP-1 activation was still evident $3 \mathrm{~d}$ after injury. $B$, Effect of MP and RU486 on AP-1 binding activity after SCI. Rats were treated with or without MP (30 $\mathrm{mg} / \mathrm{kg}$, i.v.; $15 \mathrm{~min}$ after injury). In some MP-treated animals, pretreatment with RU486 (15 mg/kg, i.p.; 30 min before injury) was given. Lanes 1, Free probe; 2, sham-operated control; 3, normal control; 4, SCI; 5, SCI + MP; and 6, SCI + RU486 + MP. Note MP inhibition of post-traumatic AP-1 activation. This MP effect was reversed by RU486 pretreatment. Data shown in $A$ and $B$ are representative of three separate experiments with similar results.

1995; Leech et al., 1998). RU486 also reversed the inhibitory effect of MP on AP-1 activation after SCI (Fig. 1B).

\section{Cellular localization of components of AP-1}

AP-1 is either a heterodimer of Fos and Jun proteins or a homodimer of Jun family proteins. To study cellular distribution of AP-1 activation, immunohistochemical studies were conducted using antibodies against Fos-B and c-Jun, the representative components of AP-1. Fos-B and c-Jun expression was intense in the injured cord $8 \mathrm{hr}$ after injury as compared with very weak Fos-B (Fig. 2A,B) immunoreactivity in the sham-operated cord. Little c-Jun immunoreactivity was detected in the sham-operated cord (data not shown). Fos-B and c-Jun immunoreactivity was localized to nucleus and cytoplasm of cells in both gray and white matter in the injured cord (Fig. 2D-G). The specificity of Fos-B immunoreactivity was confirmed by the antibody preabsorption experiment in which the primary Fos-B antibody was preincubated with exogenous Fos-B antigen. This treatment resulted in the disappearance of Fos-B immunoreactivity (Fig. 2C). c-Jun immunoreactivity was eliminated when the primary antibody was omitted (data not shown) from the immunostaining process.

\section{Effect of c-fos antisense ODN on AP-1 and NF- $\mathrm{B}$ binding activity}

To further confirm the specificity of AP-1 binding in vivo, we used an antisense strategy directed at $c$-fos to decrease AP-1 activation as has been successfully shown in a brain injury model (Liu et al., 1994; Cui et al., 1999). The same strategy, entailing an in vivo transfection of a $c$-fos antisense ODN, reduced post-traumatic activation of AP-1 (Fig. $3 A$ ). To reduce nonspecific ODN effects, a $c$-fos sense ODN was also tested and showed no effect on AP-1 activation after SCI (Fig. $3 A$ ). The specificity of the $c$-fos antisense ODN on AP-1 activity was supported by the observation that it did not affect NF- $\kappa$ B activation after SCI (Fig. $3 B$ ).

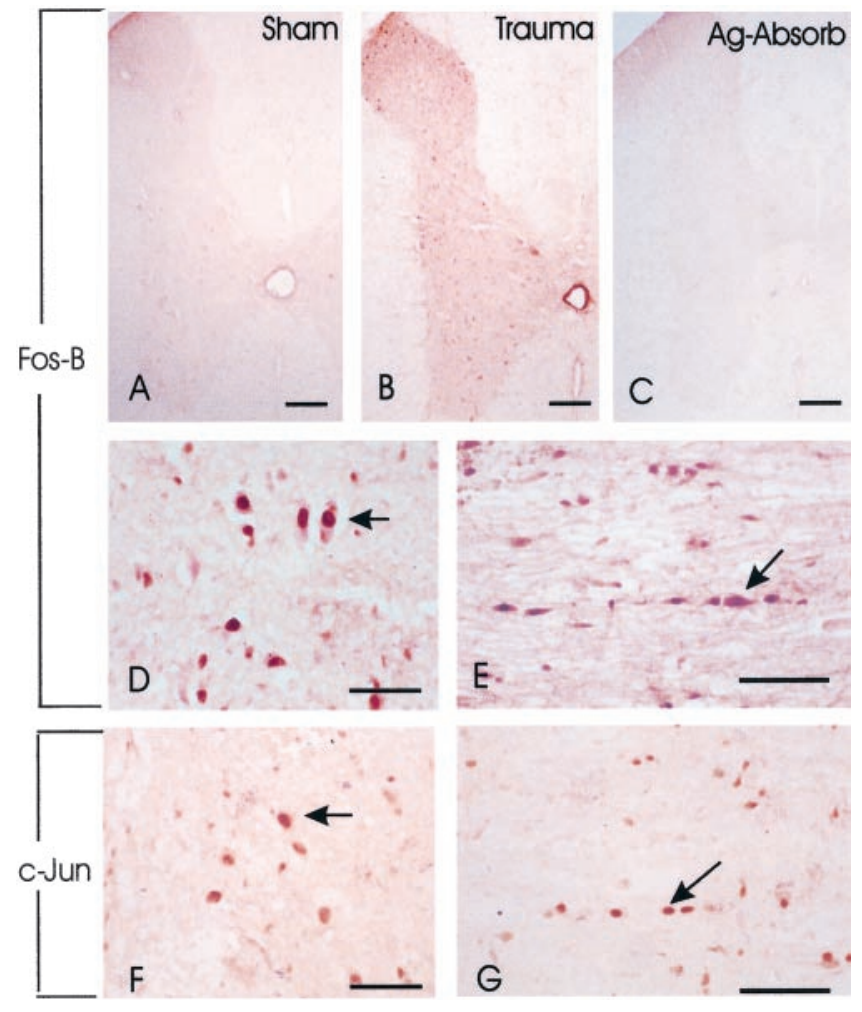

Figure 2. Increase in Fos-B and c-Jun immunoreactivity after SCI. $A$, In a sham-operated cord segment, little Fos-B immunoreactivity was detected. $B$, Fos-B immunoreactivity was intense in a section of the injured cord 7 $\mathrm{mm}$ rostral to the epicenter; $8 \mathrm{hr}$ after SCI. $C$, Preabsorption with Fos-B in a section adjacent to the section shown in $B$ resulted in the disappearance of Fos-B immunoreactivity. $D, E$, Fos-B immunoreactivity was detected in both the gray $(D)$ and white $(E)$ matter in the injured cord, $5 \mathrm{~mm}$ distal to the epicenter. $F, G$, c-Jun expression was also detected in the gray $(F)$ and white $(G)$ matter, in areas corresponding to $D$ and $E$. Note that Fos-B and c-Jun immunoreactivity could be localized in the cytoplasm and more intensely in the nucleus of cells with morphology suggestive of neurons in the gray matter $(D, F)$ and glial cells in the white matter $(F, G)$. Results shown are representative of two separate experiments with similar results. Scale bars: $A-C, 150 \mu \mathrm{m} ; D, F, 75 \mu \mathrm{m} ; E, G, 100 \mu \mathrm{m}$.

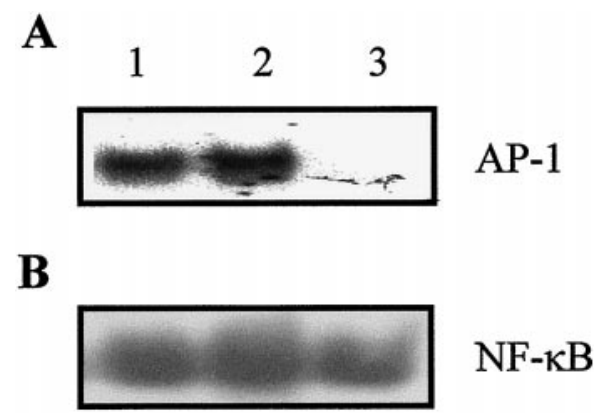

Figure 3. Effect of c-fos antisense and sense ODN on AP-1 and NF- $\kappa$ B binding activity. Rats were treated with c-fos antisense or sense ODN or vehicle (lipofectin only) $16 \mathrm{hr}$ before SCI. The injured cord segment was sampled for AP-1 or NF- $\kappa$ B binding activity by EMSA $8 \mathrm{hr}$ after SCI. Lanes 1, Lipofectin; 2, c-fos sense ODN; and 3, c-fos antisense ODN. Note $c$-fos antisense ODN treatment blocked post-traumatic increase in AP-1 (top panel) but not NF- $\kappa \mathrm{B}$ (bottom panel) binding activity. Data shown are representative of three separate experiments with similar results.

\section{MMP-1 and MMP-9 expression after SCI}

MMP-1 and MMP-9 are expressed in inflammation (Brenner et al., 1989; Vu and Werb, 1998). Genes encoding these two pro- 

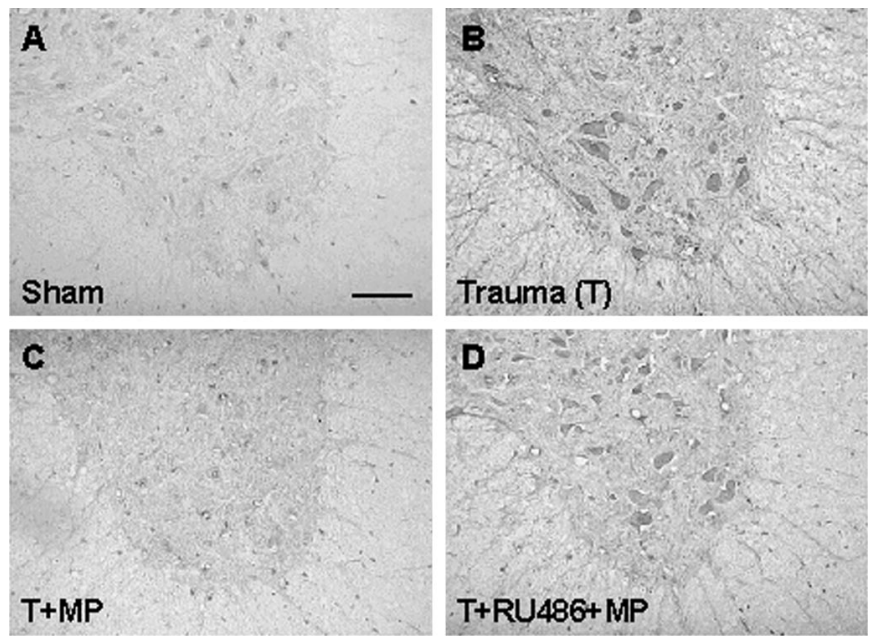

Figure 4. MMP-1 expression after SCI. A, Sham-operated control showing little MMP-1 immunoreactivity. $B$, Intense MMP-1 expression $1 \mathrm{~d}$ after $\mathrm{SCI}$ in a section $5 \mathrm{~mm}$ rostral to the epicenter. $C$, MP suppression of MMP-1 expression in a cord section corresponding to $B$ from an animal treated with MP. D, RU486 reversal of MP inhibition of MMP-1 expression after SCI in a section corresponding to $B$ in an animal pretreated with RU486 and post-treated with MP. Results shown are representative of three separate experiments with similar results. Scale bar, $100 \mu \mathrm{m}$ for all panels.
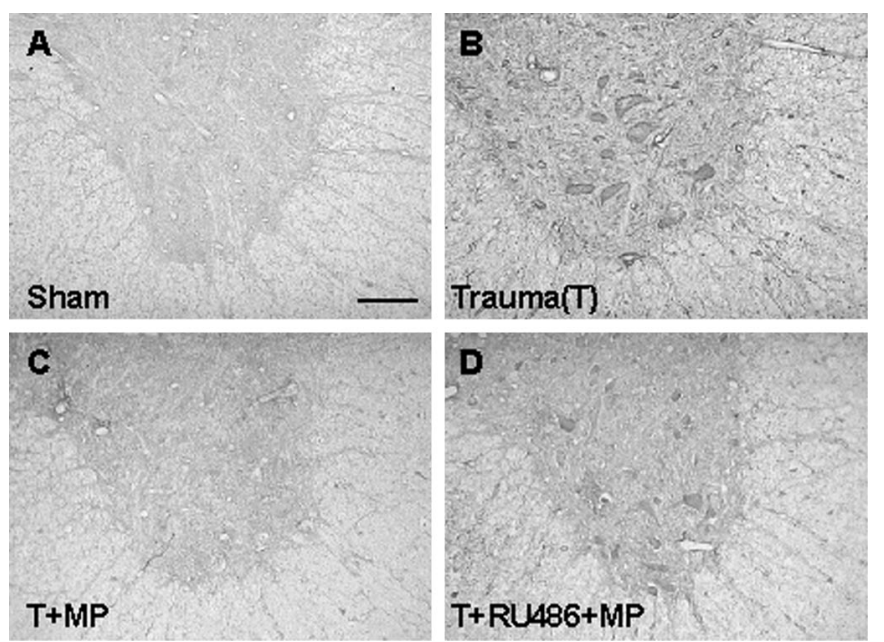

Figure 5. MMP-9 expression after SCI. A, Sham-operated control. B, Increased expression of MMP-9 $1 \mathrm{~d}$ after SCI in a cord section $5 \mathrm{~mm}$ rostral to the epicenter. $C$, MP suppression of MMP-9 expression in a cord section corresponding to $B$ from an animal treated with MP. $D$, RU486 reversal of MP inhibition of MMP-9 expression after SCI in a section corresponding to $B$ in an animal pretreated with RU486 and post-treated with MP. Results shown are representative of three separate experiments with similar results. Scale bar, $100 \mu \mathrm{m}$ for all panels.

teases are transactivated jointly by AP-1 and NF- $\kappa \mathrm{B}$ (Yokoo and Kitamura, 1996; Bond et al., 1998, 1999; Vincenti et al., 1998). With the demonstration of AP-1 activation in the present study and previous report of NF- $\kappa \mathrm{B}$ activation after SCI (Bethea et al., 1998; Xu et al., 1998), we expected transactivation of MMP-1 and MMP-9 genes by AP-1 and NF- $\kappa$ B after SCI. Immunohistochemical studies showed increased expression of MMP-1 (Fig. 4) and MMP-9 (Fig. 5). During their peak expression, both MMP-1 and MMP-9 were expressed with high intensity in neurons and glial cells after SCI. Immunohistochemical demonstration of MMP-1
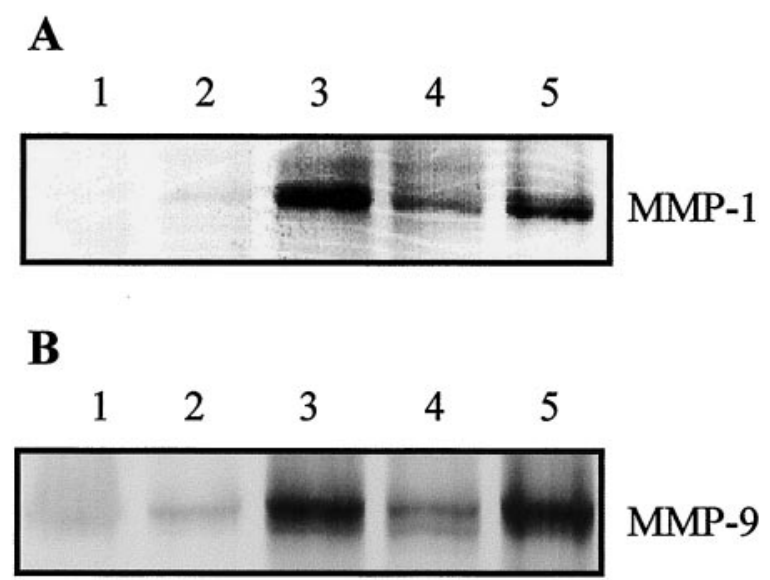

Figure 6. Western blot analysis showing effects of MP and RU486 on MMP-1 and MMP-9 expression after SCI. A, MMP-1. B, MMP-9. The injured cord segment was sampled for Western blot analysis $1 \mathrm{~d}$ after SCI. For both $A$ and $B$, Lanes 1, Normal control; 2, sham-operated control; 3, SCI; 4, SCI + MP; and 5, RU486 + SCI + MP. Note MP suppression of MMP-1 and MMP-9 expression after SCI and RU486 reversal of the MP effect. Each lane represents a sample obtained from one individual rat. Data shown are representative of three separate experiments with similar results.

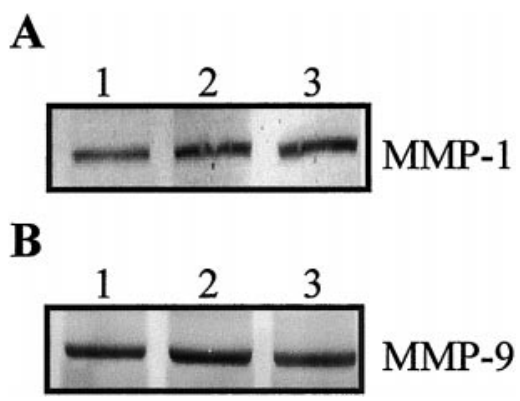

Figure 7. The effect of c-fos antisense and sense ODNs on MMP-1 and MMP-9 expression after SCI. Rats were treated with vehicle (lipofectin), $c$-fos sense, or antisense ODN $16 \mathrm{hr}$ before SCI. The injured cord segment was sampled for Western blotting $1 \mathrm{~d}$ after SCI. $A$, MMP-1. B, MMP-9. For both $A$ and $B$, Lanes 1 , Lipofectin vehicle; 2, sense ODN; and 3, antisense ODN. Note no difference in intensity of MMP-1 or MMP-9 expression among the three groups. Each lane represents a sample obtained from one individual rat. Data shown are representative of three separate experiments with similar results.

and MMP-9 expression was confirmed by Western blotting (Fig. 6).

\section{Effects of MP and RU486 on MMP-1 and MMP-9 expression after $\mathrm{SCI}$}

GCs including MP have been shown to suppress the activation of both AP-1 and NF- $\kappa$ B in inflammatory disorders (Barnes, 1998). MP has also been shown to inhibit NF- $\kappa \mathrm{B}$ (Xu et al., 1998) and AP-1 activation (Fig. 1B). Thus, MP was anticipated to repress post-traumatic expression of MMP-1 and MMP-9. Our results are in accordance with this prediction. MP inhibited posttraumatic increase in MMP-1 and MMP-9 expression as shown by immunohistochemistry (Figs. 4, 5) and Western blotting (Fig. 6). RU486 pretreatment reversed this MP effect (Figs. 4-6). The antisense $c$-fos ODN, which selectively blocked AP-1, but not $\mathrm{NF}-\kappa \mathrm{B}$ activation failed to repress MMP-1 and MMP9 expression after SCI (Fig. 7). 


\section{DISCUSSION}

An inflammatory reaction has been extensively documented in animal models of SCI (Balentine, 1978a,b; Means and Anderson, 1983; Xu et al., 1990; Blight, 1992; Dusart and Schwab, 1994; Bartholdi and Schwab, 1995; Hamada et al., 1996; Popovich et al., 1996, 1997; Zhang et al., 1997). NF- $\mathrm{B}$ and AP-1 are two major proinflammatory transcription factors that are activated in inflammation (Barnes and Karin, 1997; Karin et al., 1997). We (Xu et al., 1998) and others (Bethea et al., 1998) have shown earlier that $\mathrm{NF}-\kappa \mathrm{B}$ was activated after SCI in a rat model. In the present study, we noted that AP-1 was also activated after SCI starting as early as $1 \mathrm{hr}$ and peaking at $8 \mathrm{hr}$ after injury. Elevated AP-1 binding activity was noted for at least $3 \mathrm{~d}$ after injury. Immunocytochemical studies revealed the increased expression of Fos and Jun family proteins. These constituent components of AP-1 were not only localized to the cytosol but also in nuclei, suggesting their nuclear translocation to form the AP-1 transcription factor. The specificity of the observed AP- 1 activation was confirmed by an antisense strategy directed at $c$-fos that blocked AP-1 activation after SCI. To our knowledge, the present study is the first to report AP-1 activation after SCI.

AP-1 transactivates a large set of genes (Sharp, 1994), including MMP-1 (Brenner et al., 1989; Jonat et al., 1990; Schule et al., 1990; Yang-Yen et al., 1990) and MMP-9 (Sato et al., 1993; Yokoo and Kitamura, 1996). Recent studies indicate that activation of both AP-1 and NF- $\kappa$ B are required for the transactivation of MMP-1 (Vincenti et al., 1998; Bond et al., 1999) and MMP-9 genes (Yokoo and Kitamura, 1996; Bond et al., 1998). Because both AP-1 (Fig. 1 $A$ ) and NF- $\kappa$ B (Bethea et al., 1998; Xu et al., 1998) were activated after SCI, it was expected that MMP-1 and MMP-9 should also be transactivated after SCI. This contention was supported by immunohistochemical studies and Western blot analysis. MMP-1 and MMP-9 immunoreactivity was localized to neurons and glial cells. MMP-1 plays a major role in tissue destruction in inflammation (Davis et al., 1984; Postlethwaite et al., 1993). However, as inflammation is resolving, MMP-1 may also contribute to tissue repair and remodeling (Henson and Johnston, 1987; Alexander and Werb, 1989). MMP-9, another inflammatory gene downstream of AP-1, degrades the extracellular matrix component of basement membrane leading to the loss of vascular integrity (Liotta et al., 1980; Gijbels et al., 1994). An increase in vascular permeability causing extravasation of macromolecules is a prominent feature of inflammation and has been shown after SCI (Hsu et al., 1985).

The activation of two key proinflammatory transcription factors, $\mathrm{NF}-\kappa \mathrm{B}$ and AP-1, after SCI provides an underlying molecular mechanism for a post-traumatic inflammatory reaction. MP, a synthetic GC and the only therapeutic agent approved by FDA for treating acute traumatic SCI in humans, shares the potent antiinflammatory properties of GCs. The anti-inflammatory action of GCs is mediated by inhibition of NF- $\kappa$ B and AP-1 activation via a GR mechanism (Jonat et al., 1990; Schule et al., 1990; Yang-Yen et al., 1990; Ray and Prefontaine, 1994; Caldenhoven et al., 1995; Scheinman et al., 1995). We have shown that MP was effective in inhibiting post-traumatic $\mathrm{NF}-\kappa \mathrm{B}$ activation (Xu et al., 1998). In the present study, we further demonstrated that MP is capable of suppressing AP-1 activation (Fig. 1B). This inhibitory action of $\mathrm{MP}$ on the two key proinflammatory transcription factors is likely to contribute to the known anti-inflammatory effects of MP in SCI as has been noted in rat SCI models (Xu et al., 1992; Bartholdi and Schwab, 1995). The consequence of MP inhibition of proinflam- matory transcription factors is the transrepression of downstream proinflammatory genes. We have shown that MP inhibition of $\mathrm{NF}-\kappa \mathrm{B}$ activation after SCI was accompanied by the transrepression of NF- $\kappa \mathrm{B}$ regulated inflammatory genes, such as TNF- $\alpha(\mathrm{Xu}$ et al., 1998). Because AP-1 and NF- $\kappa$ B transactivate MMP-1 (Vincenti et al., 1998; Bond et al., 1999) and MMP-9 (Sato et al., 1993; Yokoo and Kitamura, 1996; Bond et al., 1998) and MP inhibited NF- $\kappa \mathrm{B}$ and AP-1 activation after SCI, MP should transrepress MMP-1 and MMP-9 genes in the injured cord. Our results are in accord with this expectation and support the contention that MMP-1 and MMP-9 expression is likely driven by AP-1 and $\mathrm{NF}-\kappa \mathrm{B}$ activation after SCI. Further support for the requirement of the activation of both AP-1 and NF- $\kappa$ B for MMP-1 and MMP-9 gene transcription was derived from an antisense study. A $c$-fos antisense ODN selectively inhibited AP-1, but not $\mathrm{NF}-\kappa \mathrm{B}$, activation. This antisense ODN failed to suppress MMP-1 and MMP-9 expression. These results are in agreement with the recent findings that the activation of both $\mathrm{NF}-\kappa \mathrm{B}$ and $\mathrm{AP}-1$ are required to upregulate the expression of MMP-1 and MMP-9. The differential effects of MP versus the antisense ODN on MMP-1 and MMP-9 expression after SCI may be related to the notion that MP blocked the activation of both $\mathrm{NF}-\kappa \mathrm{B}$ and AP-1, whereas the antisense ODN only inhibited AP-1 binding activity.

Anti-inflammatory action of GC entails GC binding to cytosolic GR to form aGR that translocates into the nucleus to serve as a transcription factor. aGR interacts with NF- $\kappa$ B and AP-1 to inhibit the activity of these two transcription factors (Jonat et al., 1990; Schule et al., 1990; Yang-Yen et al., 1990; Ray and Prefontaine, 1994; Caldenhoven et al., 1995; Scheinman et al., 1995). Thus, for MP to inhibit NF- $\kappa$ B and AP-1 activation, it has to bind to GR. We have previously shown that GR expression was increased after SCI, supporting the availability of GR in the injured cord for MP action. Further support for the hypothesis that MP-induced inhibition of AP-1 is mediated by a GR mechanism comes from the finding that RU486, a potent GR antagonist, was able to reverse MP inhibition of AP-1 (Fig. $1 B$ ) and NF- $\kappa$ B (our unpublished observation) activation. Furthermore, RU486 also reversed MP inhibition of MMP-1 and MMP-9 expression after SCI. These findings are again consistent with the contention that AP- 1 and $\mathrm{NF}-\kappa \mathrm{B}$ are required to transactivate $\mathrm{MMP}-1$ and $\mathrm{MMP}-9$ and therefore are subjected to the inhibitory action of MP via a GR mechanism.

In summary, we have demonstrated post-traumatic activation of AP-1 and the induction of two inflammatory genes downstream of this transcription factor. The activation of AP-1 and $\mathrm{NF}-\kappa \mathrm{B}$, two key proinflammatory transcription factors, is likely to play a major role in transactivating inflammatory genes after SCI. The inhibitory effects of MP on post-traumatic activation of $\mathrm{NF}-\kappa \mathrm{B}$ and AP-1 and the respective downstream genes are consistent with the well documented anti-inflammatory action of GCs. Moreover, that this MP action in SCI is mediated by a GR mechanism is supported by the effectiveness of RU486, a GR antagonist, in blocking MP inhibition of AP-1 activation and MMP-1 and MMP-9 expression after SCI. Further studies are needed to causally link the anti-inflammatory action of MP to its therapeutic effects in acute SCI.

\section{REFERENCES}

Alexander CM, Werb Z (1989) Proteinases and extracellular matrix remodeling. Curr Opin Cell Biol 1:974-982.

An G, Lin TN, Liu JS, Xue JJ, He YY, Hsu CY (1993) Expression of c-fos and c-jun family genes after focal cerebral ischemia. Ann Neurol 33:457-464. 
Balentine JD (1978a) Pathology of experimental spinal cord trauma. I. The necrotic lesion as a function of vascular injury. Lab Invest $39: 236-253$.

Balentine JD (1978b) Pathology of experimental spinal cord trauma. II. Ultrastructure of axons and myelin. Lab Invest 39:254-266.

Barnes PJ (1998) Anti-inflammatory actions of glucocorticoids: molecular mechanisms. Clin Sci (Colch) 94:557-572.

Barnes PJ, Karin M (1997) Nuclear factor-kappaB: a pivotal transcription factor in chronic inflammatory diseases. $N$ Engl $\mathrm{J}$ Med 336:1066-1071.

Bartholdi D, Schwab ME (1995) Methylprednisolone inhibits early inflammatory processes but not ischemic cell death after experimental spinal cord lesion in the rat. Brain Res 672:177-186.

Basso DM, Beattie MS, Bresnahan JC, Anderson DK, Faden AI, Gruner JA, Holford TR, Hsu CY, Noble LJ, Nockels R, Perot PL, Salzman SK, Young W (1996) MASCIS evaluation of open field locomotor scores: effects of experience and teamwork on reliability. Multicenter animal spinal cord injury study. J Neurotrauma 13:343-359.

Bethea JR, Castro M, Keane RW, Lee TT, Dietrich WD, Yezierski RP (1998) Traumatic spinal cord injury induces nuclear factor-kappaB activation. J Neurosci 18:3251-3260.

Blight AR (1992) Macrophages and inflammatory damage in spinal cord injury [Review]. J Neurotrauma 9:S83-S91.

Bond M, Fabunmi RP, Baker AH, Newby AC (1998) Synergistic upregulation of metalloproteinase-9 by growth factors and inflammatory cytokines: an absolute requirement for transcription factor NF-kappa B. FEBS Lett 435:29-34.

Bond M, Baker AH, Newby AC (1999) Nuclear factor kappaB activity is essential for matrix metalloproteinase- 1 and -3 upregulation in rabbit dermal fibroblasts. Biochem Biophys Res Commun 264:561-567.

Bracken MB (1990) Methylprednisolone in the management of acute spinal cord injuries. Med J Aust 153:368.

Brenner DA, O'Hara M, Angel P, Chojkier M, Karin M (1989) Prolonged activation of jun and collagenase genes by tumour necrosis factor-alpha. Nature 337:661-663.

Caldenhoven E, Liden J, Wissink S, Van de Stolpe A, Raaijmakers J, Koenderman L, Okret S, Gustafsson JA, Van der Saag PT (1995) Negative cross-talk between RelA and the glucocorticoid receptor: a possible mechanism for the antiinflammatory action of glucocorticoids. Mol Endocrinol 9:401-412.

Chiu R, Boyle WJ, Meek J, Smeal T, Hunter T, Karin M (1988) The c-Fos protein interacts with c-Jun/AP-1 to stimulate transcription of AP-1 responsive genes. Cell 54:541-552.

Cui JK, Hsu CY, Liu PK (1999) Suppression of postischemic hippocampal nerve growth factor expression by a c-fos antisense oligodeoxynucleotide. J Neurosci 19:1335-1344.

Davis WB, Fells GA, Sun XH, Gadek JE, Venet A, Crystal RG (1984) Eosinophil-mediated injury to lung parenchymal cells and interstitial matrix. A possible role for eosinophils in chronic inflammatory disorders of the lower respiratory tract. J Clin Invest 74:269-278.

Dignam JD, Lebovitz RM, Roeder RG (1983) Accurate transcription initiation by RNA polymerase II in a soluble extract from isolated mammalian nuclei. Nucleic Acids Res 11:1475-1489.

Dusart I, Schwab ME (1994) Secondary cell death and the inflammatory reaction after dorsal hemisection of the rat spinal cord. Eur J Neurosci 6:712-724

Gijbels K, Galardy RE, Steinman L (1994) Reversal of experimental autoimmune encephalomyelitis with a hydroxamate inhibitor of matrix metalloproteases. J Clin Invest 94:2177-2182.

Gruner JA (1992) A monitored contusion model of spinal cord injury in the rat. J Neurotrauma 9:123-126.

Halazonetis TD, Georgopoulos K, Greenberg ME, Leder P (1988) c-Jun dimerizes with itself and with c-Fos, forming complexes of different DNA binding affinities. Cell 55:917-924.

Hall ED, Braughler JM (1981) Acute effects of intravenous glucocorticoid pretreatment on the in vitro peroxidation of cat spinal cord tissue. Exp Neurol 73:321-324.

Hamada Y, Ikata T, Katoh S, Nakauchi KJ, Niwa M, Kawai Y, Fukuzawa KJ (1996) Involvement of an intercellular adhesion molecule 1-dependent pathway in the pathogenesis of secondary changes after spinal cord injury in rats. J Neurochem 66:1525-1531.

Henson PM, Johnston RBJ (1987) Tissue injury in inflammation. Oxidants, proteinases, and cationic proteins. J Clin Invest 79:669-674.

Hsu CY, Dimitrijevic MR (1990) Methylprednisolone in spinal cord injury: the possible mechanism of action. J Neurotrauma 7:115-119.

Hsu CY, Hogan EL, Gadsden RHS, Spicer KM, Shi MP, Cox RD (1985) Vascular permeability in experimental spinal cord injury. J Neurol Sci 70:275-282.

Jewell CM, Webster JC, Burnstein KL, Sar M, Bodwell JE, Cidlowski JA (1995) Immunocytochemical analysis of hormone mediated nuclear translocation of wild type and mutant glucocorticoid receptors. J Steroid Biochem Mol Biol 55:135-146.

Jonat C, Rahmsdorf HJ, Park KK, Cato AC, Gebel S, Ponta H, Herrlich P (1990) Antitumor promotion and antiinflammation: down-modulation of AP-1 (Fos/Jun) activity by glucocorticoid hormone. Cell 62:1189-1204.
Karin M, Liu ZG, Zandi E (1997) AP-1 function and regulation. Curr Opin Cell Biol 9:240-246.

Laue L, Kawai S, Brandon DD, Brightwell D, Barnes K, Knazek RA, Loriaux DL, Chrousos GP (1988) Receptor-mediated effects of glucocorticoids on inflammation: enhancement of the inflammatory response with a glucocorticoid antagonist. J Steroid Biochem 29:591-598.

Leech M, Hutchinson P, Holdsworth SR, Morand EF (1998) Endogenous glucocorticoids modulate neutrophil migration and synovial P-selectin but not neutrophil phagocytic or oxidative function in experimental arthritis. Clin Exp Immunol 112:383-388.

Liotta LA, Tryggvason K, Garbisa S, Hart I, Foltz CM, Shafie S (1980) Metastatic potential correlates with enzymatic degradation of basement membrane collagen. Nature 284:67-68.

Liu PK, Salminen A, He YY, Jiang MH, Xue JJ, Liu JS, Hsu CY (1994) Suppression of ischemia-induced fos expression and AP-1 activity by an antisense oligodeoxynucleotide to c-fos mRNA. Ann Neurol 36:566-576.

Liu XZ, Xu XM, Hu R, Du C, Zhang SX, McDonald JW, Dong HX, Wu YJ, Fan GS, Jacquin MF, Hsu CY, Choi DW (1997) Neuronal and glial apoptosis after traumatic spinal cord injury. J Neurosci 17:5395-5406.

Means ED, Anderson DK (1983) Neuronophagia by leukocytes in experimental spinal cord injury. J Neuropathol Exp Neurol 42:707-719.

Nesathurai S (1998) Steroids and spinal cord injury: revisiting the NASCIS 2 and NASCIS 3 trials. J Trauma 45:1088-1093.

Popovich PG, Stokes BT, Whitacre CC (1996) Concept of autoimmunity following spinal cord injury - possible roles for t lymphocytes in the traumatized central nervous system [Review]. J Neurosci Res 45:349-363.

Popovich PG, Wei P, Stokes BT (1997) Cellular inflammatory response after spinal cord injury in Sprague-Dawley and Lewis rats. J Comp Neurol 377:443-464.

Postlethwaite AE, Lachman LB, Mainardi CL, Kang AH (1993) Interleukin 1 stimulation of collagenase production by cultured fibroblasts. $\mathrm{J}$ Exp Med 157:801-806.

Ray A, Prefontaine KE (1994) Physical association and functional antagonism between the p65 subunit of transcription factor NF-kappa B and the glucocorticoid receptor. Proc Natl Acad Sci USA 91:752-756.

Sato H, Kita M, Seiki M (1993) v-Src activates the expression of 92-kDa type IV collagenase gene through the AP-1 site and the GT box homologous to retinoblastoma control elements. A mechanism regulating gene expression independent of that by inflammatory cytokines. J Biol Chem 268:23460-23468.

Scheinman RI, Gualberto A, Jewell CM, Cidlowski JA, Baldwin ASJ (1995) Characterization of mechanisms involved in transrepression of NF-kappa B by activated glucocorticoid receptors. Mol Cell Biol 15:943-953.

Schule R, Rangarajan P, Kliewer S, Ransone LJ, Bolado J, Yang N, Verma IM, Evans RM (1990) Functional antagonism between oncoprotein c-Jun and the glucocorticoid receptor. Cell 62:1217-1226.

Sharp FR (1994) The sense of antisense fos oligonucleotides. Ann Neurol 36:555-556

Vincenti MP, Coon CI, Brinckerhoff CE (1998) Nuclear factor kappaB/ p50 activates an element in the distal matrix metalloproteinase 1 promoter in interleukin-1beta-stimulated synovial fibroblasts. Arthritis Rheum 41:1987-1994.

Vu TH, Werb Z (1998) Gelatinase B: structure, regulation, and function. In: Matrix metalloproteinases (Parks W, Mecham R, eds), p 115-148. San Diego: Academic.

Wisdom R (1999) AP-1: one switch for many signals. Exp Cell Res 253:180-185.

Xu J, Liu TH, Hogan EL, Perot PL, Hsu CY (1990) Leukotriene B4 and polymorphonuclear cell infiltration in spinal cord injury. J Neurochem 55:907-912.

Xu J, Qu ZX, Hogan EL, Perot PLJ (1992) Protective effect of methylprednisolone on vascular injury in rat spinal cord injury. J Neurotrauma $9 \cdot 245-253$

Xu J, Fan G, Chen S, Wu Y, Xu XM, Hsu CY (1998) Methylprednisolone inhibition of TNF-alpha expression and NF-kB activation after spinal cord injury in rats. Mol Brain Res 59:135-142.

Yan P, Xu J, Li Q, Chen S, Kim GM, Hsu CY, Xu XM (1999) Glucocorticoid receptor expression in the spinal cord after traumatic injury in adult rats. J Neurosci 19:9355-9363.

Yang K, Mu XS, Xue JJ, Whitson J, Salminen A, Dixon CE, Liu PK, Hayes RL (1994) Increased expression of c-fos mRNA and AP-1 transcription factors after cortical impact injury in rats. Brain Res 664:141-147.

Yang-Yen HF, Chambard JC, Sun YL, Smeal T, Schmidt TJ, Drouin J, Karin M (1990) Transcriptional interference between c-Jun and the glucocorticoid receptor: mutual inhibition of DNA binding due to direct protein-protein interaction. Cell 62:1205-1215.

Yokoo T, Kitamura M (1996) Dual regulation of IL-1 beta-mediated matrix metalloproteinase-9 expression in mesangial cells by NF-kappa B and AP-1. Am J Physiol 270:F123-F130.

Yong VW, Krekoski CA, Forsyth PA, Bell R, Edwards DR (1998) Matrix metalloproteinases and diseases of the CNS. Trends Neurosci 21:75-80.

Zhang Z, Krebs CJ, Guth L (1997) Experimental analysis of progressive necrosis after spinal cord trauma in the rat: etiological role of the inflammatory response. Exp Neurol 143:141-152. 